\title{
The study of elastic properties and chemical composition of selected rocks
}

\author{
Sandra Herber, Iwona Stan-Kłeczek ${ }^{*}$ \\ Department of Applied Geology, Faculty of Earth Sciences, University of Silesia, 60 Bedzinska Str, 41-200 \\ Sosnowiec, Poland \\ "Corresponding author: istan@us.edu.pl
}

Received: $30^{\text {th }}$ April, 2018

Accepted: $11^{\text {th }}$ May, 2018

\begin{abstract}
The aim of the investigation was to study the elastic properties and chemical composition of rock samples based on laboratory measurements. Three cuboid samples of diabase, granite and quartz were tested under laboratory conditions. The shape of samples is a cuboid with dimensions $0.1 \times 0.05 \times 0.05 \mathrm{~m}$ and the measurements were made in three directions. The Pundit Lab+ equipment was used for tests.

The signal frequency value was $250 \mathrm{kHz}$. The propagation times of $\mathrm{P}$ - and $\mathrm{S}$-waves were designated that allows to determine the elastic dynamic moduli values. The Japanese JEOL USA Scanning Electron Microscope was also used for tests. The chemical composition of rocks were determined by characteristic X-rays analysis. Obtained results show that the ultrasonic measurements and SEM are useful tools to assign properties of rocks. This knowledge makes easier recognition in preliminary stages during engineering study.
\end{abstract}

Key words: Ultrasonic measurement, elastic dynamic moduli, chemical composition, characteristic X-rays analysis

\section{Introduction}

A rock is a solid aggregate of interlocking minerals and it has got a skeleton which shows elastic properties too. A small deformation of rock sample doesn't cause non-elastic deformation: a sample of rock comes back to its original shape and size. The relationship between stress and strain is described by elastic properties (Gueguen and Schubnel, 2003). They are divided into two groups: static and dynamic. Static elastic properties of rock are generally lower in value than dynamic (Pinińska, 2000; Pinińska and Płatek, 2002; Lavrentyev and Rokhlin, 2001; Mogilevskaya et al., 2007; Živor et al., 2011; Hammam and Eliwa, 2013; Saxena and Mavko, 2016). A discrepancy between these values is associated with heterogeneous microstructure of the rock, difference in amplitude of strain and frequency applied during survey. Elastic parameters are determined during measurements in static conditions (Najibi et al., 2015). A study of Pand $\mathrm{S}$ - waves velocity values and density calculation or seismic survey are methods of determining elastic parameters. The theory of elastic-wave propagation assumes that medium is homogeneous, isotropic, infinitely extended and perfectly elastic (Elbra et al., 2011) . However, naturally occurring rocks haven't got sufficient properties, which the theory requires (Bukowska and Sanetra, 2008, Fener, 2011). Rocks have got a differential chemical and mineralogical composition, for example, granite samples from the same quarry could have different quartz content. They are also different conditions of formation, arrangement of mineral grains, kind of medium which fills the porous space, presence of fractures and 
another ones: all these features make the sample of rock unique (Zhu et al. 2017; Stan-Kkeczek 2016; Lednická and Kaláb, 2012; Markov et al. 2014; Mockovčiaková and Pandula 2003).

Values of elastic properties of sedimentary rocks are least of all rock groups (Pinińska 2000). Particularly small longitudinal waves velocities or Young modulus values are demonstrated by high-porosity, minor-density varieties, and high values by low-porosity relatively dense samples of sandstones, limestones, dolomites and other sedimentary rocks (Stan-Kłeczek, 2016). Metamorphic and igneous rocks are characterised by lowporosity, but in these types of rocks important factors are kind of porous medium and elastic properties of skeleton.

Dynamic elastic properties such as: Young modulus (E), Poisson ration (v), shear modulus (G) and bulk modulus (K) are calculated using knowledge of density $(\rho)$, longitudinal $\left(v_{p}\right)$ and shear $\left(v_{s}\right)$ waves velocities of a rock (Kearey and Brooks, 1991):

$$
E=3 K(1-2 v)
$$

$$
\begin{aligned}
& v=\frac{\mathrm{v}_{\mathrm{p}}^{2}-2 \mathrm{v}_{\mathrm{s}}^{2}}{2\left(\mathrm{v}_{\mathrm{p}}^{2}-\mathrm{v}_{\mathrm{s}}^{2}\right)} \\
& K=\rho\left(\mathrm{v}_{\mathrm{p}}^{2}-\frac{4}{3} \mathrm{v}_{\mathrm{s}}^{2}\right)
\end{aligned}
$$

Using all of this relationships Young's modulus could be calculated as:

$E=\frac{\rho v_{\mathrm{s}}^{2}\left(3 \mathrm{v}_{\mathrm{p}}^{2}-4 \mathrm{v}_{\mathrm{s}}^{2}\right)}{\left(\mathrm{v}_{\mathrm{p}}^{2}-\mathrm{v}_{\mathrm{s}}^{2}\right)}$

The coefficient of anisotropy $\mathrm{k}$ was calculated as a difference between the highest and the lowest value of wave velocity and the highest value of velocity (Stan-Kłeczek, 2016). In surveys three rock specimens were measured: Permian diabase from "Niedźwiedzia Góra" deposit, Palaeozoic granite from "Źółkiewka I" deposit, which is located in Strzegom town. The third sample: Palaeozoic quartz is from the Czech part of Sudetes from Orlik Massif. The deposit locations have been adequately presented in the Fig.1.

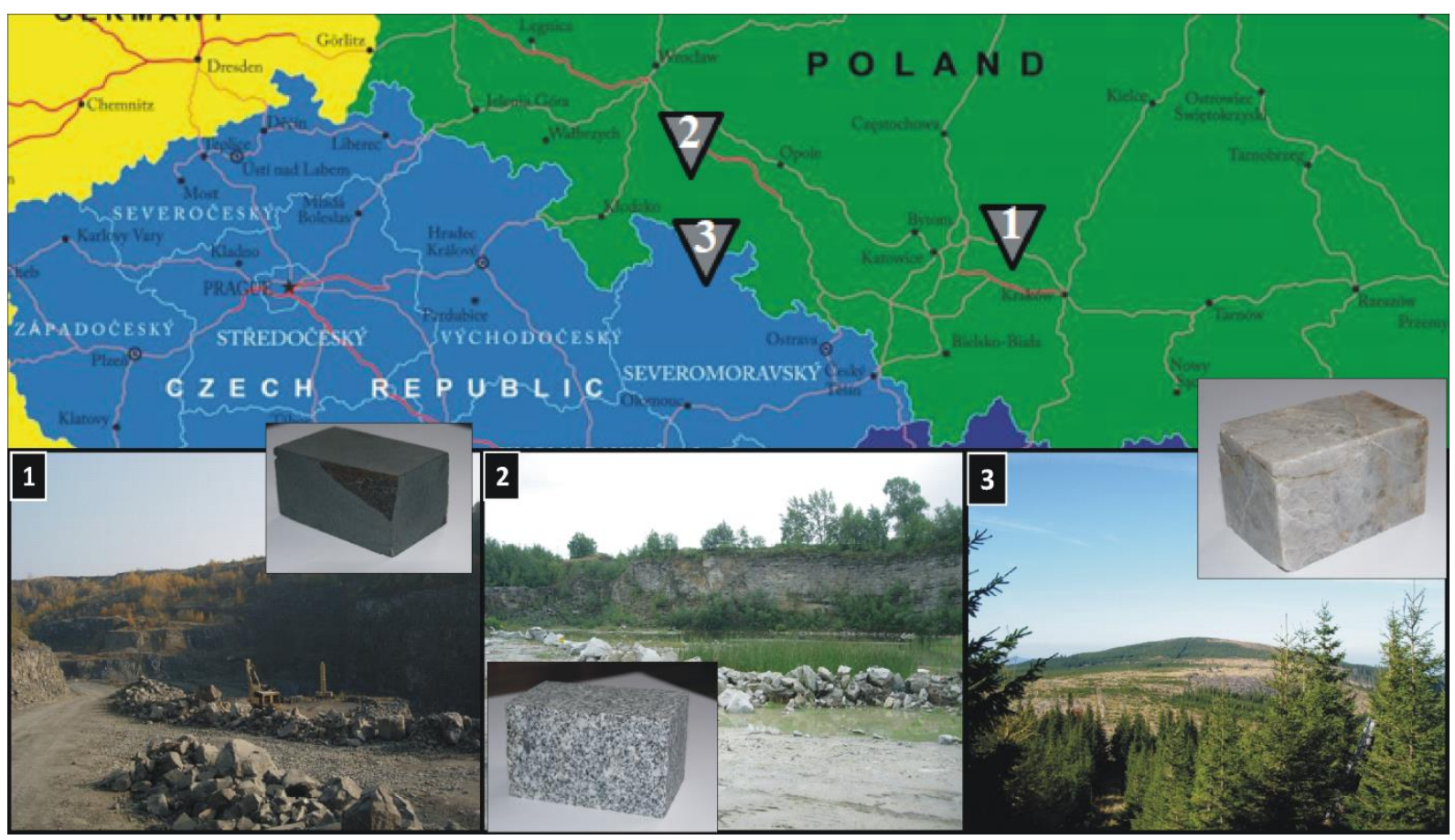

Fig. 1. Localisation of the study area: 1 - "Niedźwiedzia Góra” deposit, 2 - "Źółkiewka I" deposit, 3 - the Orlik massif with Orlik peak. (photo: I. Stan-Kłeczek) 
The ultrasonic measurement is a nondestructive method, which is used to study the elastic properties of rocks. The measurements were done in the Institute of Geonics of the Czech Academic of Science. There were two transducers: for $\mathrm{P}-$ and $\mathrm{S}-$ waves. The ultrasonic impulses are repeatedly transmitted to the sample and then recorded at the time $(t)$ of the ultrasonic wave passing through the sample. The rock specimens were mounted between the transmitter and receiver transducer holders. The length of the sample is a track (s). It is possible to calculate the velocity (v) using the formula $v=s / t$. At the beginning a special gel is applied to the sample, it provides better contact, the signal is not so much suppressed. The measurements were done, after calibration, in three, perpendicular to samples plane ways. The axes show the survey direction (Fig.2.). The frequency of signal was $250 \mathrm{kHz}$, the pulse length was $2 \mu \mathrm{s}$.

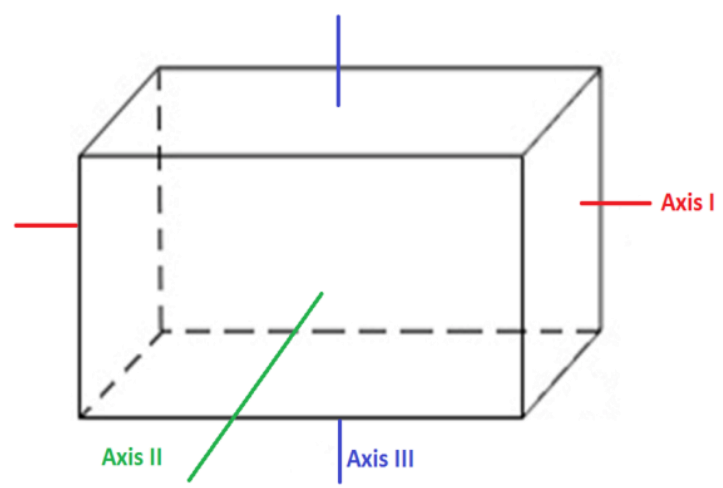

Fig. 2. The orientations of axes.

A scanning electron microscope use a focused electrons beam to scanning the sample surface. These particles interact with sample atoms and various signals are produced (Vernon-Parry, 2000; Stokes, 2008). The response of sample contain information about the sample's surface topography and composition (characteristic X-rays analysis). Samples for SEM have to be conductive, at least at the surface and electrically grounded. The rocks are nonconductive materials, so specimens were placed on a coal flake and coated with an ultrathin coating of gold. These actions prevent accumulation of electrostatic charge.

\section{Laboratory measurements and discussion}

From blocks, which were brought from each quarry, the cuboids were cut out. The rock dimensions and weight were measured. These allowed to calculate the volume and density of the samples (Tab.1). The uncertainty of mass measurement was appointed by standard deviation method and the uncertainties of volume and density were appointed by total differential.

Tab.1. The parameters of tested rocks.

\begin{tabular}{rccc}
\hline & Diabase & Granite & Quartz \\
\hline $\mathbf{V}\left[\mathbf{c m}^{3}\right]$ & 174.1 & 219.3 & 160.6 \\
$\Delta \mathbf{V}\left[\mathbf{c m}^{3}\right]$ & 7.0 & 2.2 & 5.3 \\
$\mathbf{m}[\mathbf{g}]$ & 485.8 & 572.7 & 421.1 \\
$\Delta \mathbf{m}[\mathbf{g}]$ & 0.1 & 0.1 & 0.1 \\
$\mathbf{d}\left[\mathbf{g} / \mathbf{c m}^{3}\right]$ & 2.79 & 2.61 & 2.62 \\
$\Delta \mathbf{d}\left[\mathbf{g} / \mathbf{c m}^{3}\right]$ & 0.11 & 0.03 & 0.09 \\
\hline
\end{tabular}

The wave velocities were calculated as a ratio of the sample length and time of signal propagation through the rock. The uncertainties of time and length were determined by standard deviation method and the uncertainties of velocity and dynamic elastic moduli were appointed by total differential (Tabs 2 and 3 ).

The areas, for which the chemical composition (all result in atomic \%) of the samples (Tab.4) were determined, are shown in the Figure 3.

\section{Discussion}

The diabase sample have got losses, but it has no visible cracks. The highest value of longitudinal wave was $5700 \mathrm{~m} / \mathrm{s}$ (axis 1) and the lowest value was about $20 \%$ smaller (axis 3). For this sample the maximum value 
Tab.2. Estimated wave velocity values for the respective axes.

\begin{tabular}{ccccccccc}
\hline & Axis & $\mathbf{v}_{\mathbf{p}} / \mathbf{v}_{\mathbf{s}}[\mathbf{1}]$ & $\mathbf{v}_{\mathbf{p} \max }[\mathbf{m} / \mathbf{s}]$ & $\mathbf{v}_{\mathbf{p m i n}}[\mathbf{m} / \mathbf{s}]$ & $\mathbf{k}[\%]$ & $\mathbf{v}_{\text {smax }}[\mathbf{m} / \mathbf{s}]$ & $\mathbf{v}_{\mathbf{s m i n}}[\mathbf{m} / \mathbf{s}]$ & $\mathbf{k}[\%]$ \\
\hline \multirow{4}{*}{ Diabase } & 1 & 1.96 & 5719.9 & 5534.2 & 3.2 & 2949 & 2889 & 2 \\
& 2 & 1.94 & 5729.4 & 5407.5 & 5.6 & 2927.4 & 2927.4 & 0 \\
& 3 & 1.61 & 4515.6 & 4515.6 & 0 & 2847.7 & 2688.6 & 5.6 \\
\multirow{4}{*}{ Granite } & 1 & 1.78 & 3815.2 & 3815.2 & 0 & 2169 & 2131.2 & 1.7 \\
& 2 & 1.54 & 3861 & 3342.7 & 13.4 & 2394.6 & 2327.4 & 2.8 \\
& 3 & 1.7 & 4330 & 4155.4 & 4 & 2538.3 & 2477.2 & 2.4 \\
\multirow{4}{*}{ Quartz } & 1 & 1.77 & 5477.1 & 5280.1 & 3.6 & 3123.1 & 3070.9 & 1.7 \\
& 2 & 1.69 & 5347.6 & 5347.6 & 0 & 3305.1 & 3090.5 & 6.5 \\
& 3 & 1.7 & 4891.5 & 4644.4 & 5.1 & 2891.8 & 2720.7 & 5.9 \\
\hline
\end{tabular}

Tab.3. Calculated elastic dynamic moduli for rock samples.

\begin{tabular}{cccccccccc}
\hline & Axis & $\mathbf{v}[\mathbf{1}]$ & $\mathbf{\Delta} \mathbf{v}[\mathbf{1}]$ & $\mathbf{E}[\mathbf{G P a}]$ & $\Delta \mathbf{E}[\mathbf{G P a}]$ & $\mathbf{K}[\mathbf{G P a}]$ & $\Delta \mathbf{K}[\mathbf{G P a}]$ & $\boldsymbol{\mu}[\mathbf{M P a}]$ & $\Delta \boldsymbol{\mu}[\mathbf{M P a}]$ \\
\hline \multirow{4}{*}{ Diabase } & 1 & 0.32 & 0.01 & 62.3 & 13.8 & 58.7 & 5.8 & 8.1 & 0.4 \\
& 2 & 0.32 & 0.05 & 63 & 19.9 & 57.7 & 15.7 & 8.2 & 0.7 \\
& 3 & 0.19 & 0.03 & 52 & 8.5 & 27.7 & 3.1 & 7.8 & 0.5 \\
\multirow{5}{*}{ Granite } & 1 & 0.27 & 0.01 & 30.4 & 1.5 & 22 & 0.6 & 5.6 & 0.1 \\
& 2 & 0.13 & 0.12 & 32.9 & 17 & 15 & 5.9 & 6.2 & 0.2 \\
& 3 & 0.23 & 0.03 & 40.9 & 7.9 & 25.6 & 3 & 6.6 & 0.1 \\
\multirow{6}{*}{ Quartz } & 1 & 0.26 & 0.02 & 62.8 & 9.6 & 44.4 & 5.2 & 8.1 & 0.3 \\
& 2 & 0.23 & 0.03 & 64.9 & 11.6 & 39.8 & 4.4 & 8.3 & 0.5 \\
& 3 & 0.24 & 0.07 & 51 & 10.7 & 32.1 & 9.2 & 7.4 & 0.6 \\
\hline
\end{tabular}

of coefficient $\mathrm{k}$ was $5,6 \%$. The ratio of longitudinal and transverse wave velocities and dynamic elastic moduli values are the lowest for axis 3 . The diabase composition is typical for this mafic, subvolcanic rock: pyroxenes (Iron, Sodium, Magnesium, Potassium, Aluminium), plagioclases (Oxygen, Calcium, Silicon, Sodium) and amphibolites (Titanium, Chlorine, Carbon). There are trace amounts of Caesium and Tungsten too.

The sample 2 (granite) has a fracture. It is parallel to axis 3 . For it the wave velocity dynamic elastic moduli values are higher than for other axes. The axis 2 shows the higher values of anisotropy coefficient $k=13,4 \%$ and Poisson's ratio and bulk modulus values are smaller. Based on the chemical composition of specimen, it can be concluded that measured granite contains: quartz, micas (Iron, Magnesium, Titanium), orthoclase (Potassium, Aluminum, Silicon) and plagioclases. A square marked place which is richer in Magnesium, Titanium and Iron than the background.

The quartz sample is the most fractured, but the coefficient $\mathrm{k}$ is not high, not indicate an anisotropy. The fractures are filled, brown discoloration are visible, probably they are oxidized iron oxides. These quartz sample has got silica, Calcium and Iron in its composition. The last two elements are inclusions, they don't occur evenly throughout the sample: in place marked as "Spectrum 2" they were not registered. 
Tab.4. The chemical composition of samples.

a) diabase

\begin{tabular}{cccccccc}
\hline Spectrum & $\mathbf{C}$ & $\mathbf{O}$ & $\mathbf{N a}$ & $\mathbf{M g}$ & $\mathbf{A l}$ & $\mathbf{S i}$ & $\mathbf{C l}$ \\
\hline \multirow{3}{*}{ Sum Spectrum } & 18.99 & 58.82 & 1.90 & 0.72 & 3.92 & 11.62 & \multirow{2}{*}{0.06} \\
\cline { 2 - 7 } & $\mathbf{K}$ & $\mathbf{C a}$ & $\mathbf{T i}$ & $\mathbf{F e}$ & $\mathbf{C e}$ & $\mathbf{W}$ & \\
\cline { 2 - 7 } & 1.02 & 0.93 & 0.26 & 1.55 & 0.08 & 0.13 \\
\hline
\end{tabular}

b) granite

\begin{tabular}{ccccccccccc}
\hline Spectrum & C & O & Na & Mg & Al & Si & Cl & K & Ti & Fe \\
\hline Sum Spectrum & 21.91 & 63.13 & 0.46 & 0.34 & 3.16 & 8.53 & 0.07 & 1.89 & 0.07 & 0.43 \\
\hline Spectrum 2 & 29.33 & 58.98 & - & 1.27 & 2.75 & 4.94 & - & 1.08 & 0.20 & 1.44 \\
\hline
\end{tabular}

c) quartz

\begin{tabular}{cccccc}
\hline Spectrum & C & O & Si & Ca & Fe \\
\hline Sum Spectrum & 24.17 & 58.94 & 16.62 & 0.15 & 0.11 \\
\hline Spectrum 2 & 31.93 & 49.68 & 18.39 & - & - \\
\hline
\end{tabular}

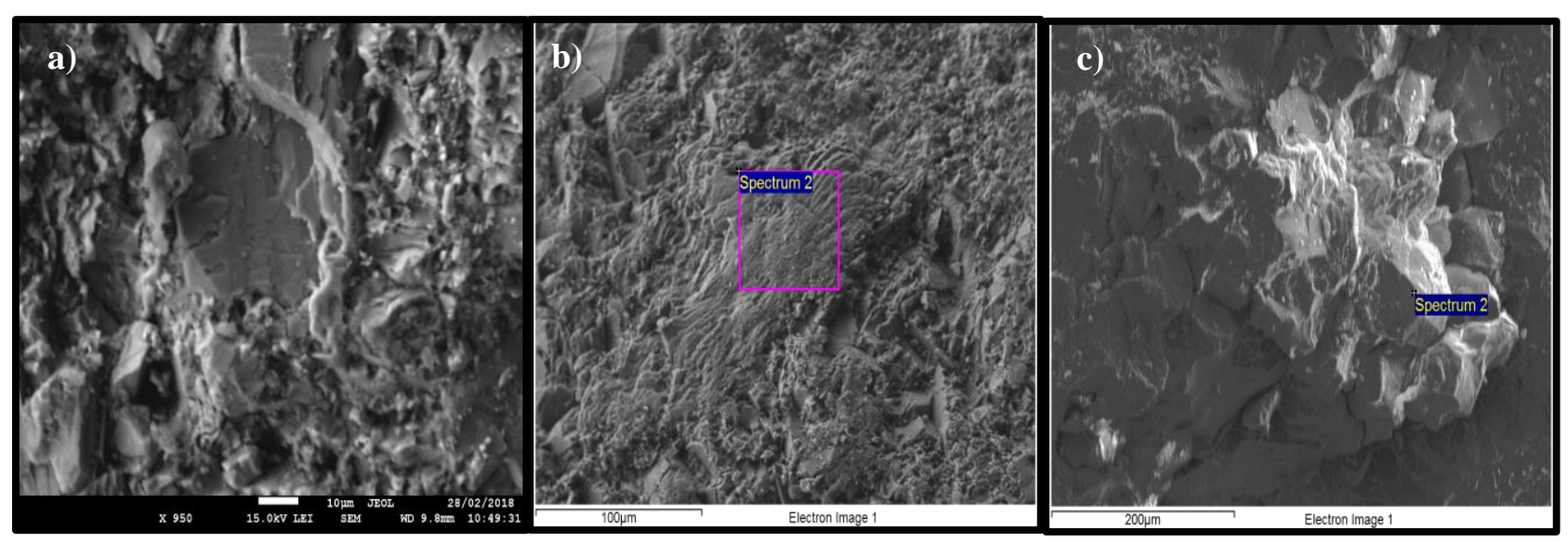

Fig.3. Electron image: a) diabase. b) granite. c) quartz.

\section{Conclusion}

Obtained results show that the ultrasonic measurements are useful tool to assign elastic modulus of rocks. The study of the elastic properties measured in the laboratory conditions provides an additional information about the physical properties of rocks. These kinds of measurements may be used as supplement or calibration of the geophysical results and/or also have importance for solving stability problems of engineering projects.

\section{References}

Bukowska M. and Sanetra U. (2008), The tests of the conventional triaxial granite and dolomite compression in the aspect of their mechanical properties, Gospodarka Surowcami Mineralnymi - Mineral Resources Management, 24(2), 345-358.

Elbra, T., Karlqvist, R., Lassila, I., Hæggström, E., \& Pesonen, L. J. (2011). Laboratory measurements of the seismic velocities and other petrophysical properties of the Outokumpu deep drill 
core samples, eastern Finland. Geophysical Journal International, 184(1), 405-415.

Fener, M. (2011). The effect of rock sample dimension on the P-wave velocity, J Nondestruct Eval 30, 99-105.

Gueguen, Y. and Schubnel, A. (2003). Elastic wave velocities and permeability of cracked rocks, Tectonophysics 370,163176.

Hammam, A.H. and Eliwa, M. (2013). Comparison between results of dynamic \& static moduli of soil determined by different methods, HBRC Journal 9, 144149.

Kearey, P. and Brooks, M. (1991) An Introduction to Geophysical Exploration, Oxford.

Lavrentyev, A. I. and Rokhlin, S. I. (2001). An ultrasonic method for determination of elastic moduli, density, attenuation and thickness of a polymer coating on a stiff plate. Ultrasonics, 39(3), 211-221.

Lednická, M. and Kaláb, Z. (2012). Evaluation of granite weathering in the Jaroným mine using non-destructive methods. Acta Geodyn.Geomater., Vol.9, No. 2(166), 211-220.

Markov, A., Ronquillo Jarillo, G., \& Markov, M. (2014). Elastic properties of rocks containing oriented systems of ellipsoidal inclusions. Journal of Applied Geophysics, 103, 114-120.

Mockovčiaková, A. and Pandula, B. (2003). Study of the relation between the static and dynamic moduli of rocks, METABK 42(1) 37, 37-39.

Mogilevskaya, S. G., Wang, J., \& Crouch, S. L. (2007). Numerical evaluation of the effective elastic moduli of rocks. International Journal of Rock Mechanics and Mining Sciences, 44(3), 425-436.
Najibi, A.R., Mohammad, G., Lashkaripour, G.R. and Asef M.R. (2015). Empirical relations between strength and static and dynamic elastic properties of Asmari and Sarvak limestones, two main oil reservoirs in Iran, Journal of Petroleum Science and Engineering 126, 78-82.

Pinińska, J. and Płatek, P. (2002). Badania ultradźwiękowe w ocenie wytrzymałościowej skał. Górnictwo odkrywkowe tom 2-3, 89-96 (in Polish).

Pinińska, J. (2000). Własności wytrzymałościowe iodształceniowe skał. Część II. Katalog. 45-70 (in Polish).

Saxena, N., \& Mavko, G. (2016). Estimating elastic moduli of rocks from thin sections: Digital rock study of 3D properties from 2D images. Computers and Geosciences, 88, 9-21.

Stan-Kłeczek, I. (2016). The study of the elastic properties of carbonate rocks on a base of laboratory and field measurement. Acta Montanistica Slovaca, 21(1), 76-83.

Stokes, D. J. (2008). Principles and Practice of Variable Pressure/Environmental Scanning Electron Microscopy (VPESEM).

Vernon-Parry, K. D. (2000). Scanning electron microscopy: an introduction. III-Vs Review, 13(4), 40-44.

Zhu, W., Shan, R., Nie, A. L., \& Peng, H. R. (2017). An efficiently dynamic stress strain simulation method on digital rock. Journal of Applied Geophysics, 147, 1015.

Živor, R, Vilhelm, J., Rudajev,V., and Lokajícek T. (2011), Measurement of Pand S- Wave Velocities in a Rock Massif and its Use in Estimation Elastic Moduli, Acta Geodynamica and Geomaterialia, 8, 2, 157-167. 